\title{
Defining Transgene Insertion Sites and Off-Target Effects of Homology-Based Gene Silencing Informs the Application of Functional Genomics Tools in Phytophthora infestans
}

\author{
Andrea L. Vu, Wiphawee Leesutthiphonchai, Audrey M. V. Ah-Fong, and Howard S. Judelson ${ }^{\dagger}$ \\ Department of Microbiology and Plant Pathology, University of California, Riverside, CA 92521, U.S.A. \\ Accepted 22 February 2019.
}

DNA transformation and homology-based transcriptional silencing are frequently used to assess gene function in Phytophthora spp. Since unplanned side-effects of these tools are not wellcharacterized, we used $P$. infestans to study plasmid integration sites and whether knockdowns caused by homology-dependent silencing spread to other genes. Insertions occurred both in gene-dense and gene-sparse regions but disproportionately near the $5^{\prime}$ ends of genes, which disrupted native coding sequences. Microhomology at the recombination site between plasmid and chromosome was common. Studies of transformants silenced for 12 different gene targets indicated that neighbors within $500 \mathrm{nt}$ were often cosilenced, regardless of whether hairpin or sense constructs were employed and the direction of transcription of the target. However, this cis spreading of silencing did not occur in all transformants obtained with the same plasmid. Genome-wide studies indicated that unlinked genes with partial complementarity with the silencinginducing transgene were not usually down-regulated. We learned that hairpin or sense transgenes were not cosilenced with the target in all transformants, which informs how screens for silencing should be performed. We conclude that transformation and gene silencing can be reliable tools for functional genomics in Phytophthora spp. but must be used carefully, especially by testing for the spread of silencing to genes flanking the target.

Keywords: genomics, oomycete-plant interactions, Phytophthora diseases

A. L. Vu, W. Leesutthiphonchai, and A. M. V. Ah-Fong made equal contributions to this work.

Nucleotide sequence data has been deposited in the NCBI database under Bioprojects PRJNA361417 and PRJNA407960.

${ }^{\dagger}$ Corresponding author: H. S. Judelson; howard.judelson@ucr.edu

Funding: This work was funded by the National Institute of Food and Agriculture grant 2018-067014-28493 and the National Science Foundation grants 1616339 and 1753749 .

The author(s) declare no conflict of interest.

(c) 2019 The American Phytopathological Society
Strategies for deciphering the roles of genes in all organisms, including plant pathogens and their hosts, involve tools for functional genomics. These approaches commonly employ gene transfer methods to knock down, knock out, or overexpress the gene of interest (Jiang et al. 2013). Contributing to the success of these tactics is an understanding of the nature of DNA transformation, including its unplanned consequences. Studies across multiple kingdoms have shown that transformation may cause chromosomal rearrangements, gene-silencing methods (including RNAi) may affect off-targets, gene editing may modify unintended loci, and regenerants may exhibit somaclonal variation (Doench et al. 2016; Firon et al. 2002; Kaelin 2012; Neelakandan and Wang 2012). An awareness of these complications helps direct the judicious use of functional genomics tools.

Methods for DNA transformation have been developed for several members of the genus Phytophthora, which includes many important phytopathogens. These eukaryotic microbes belong to the oomycete clade of the stramenopile (heterokont) group. Transformation of oomycetes was first achieved with the potato late blight pathogen $P$. infestans and, later, extended to the soybean pathogen $P$. sojae and others (Judelson et al. 1991, 1993a). The most common strategies for introducing plasmid DNA involve treating protoplasts with polyethylene glycol or electroporating zoospores (Judelson and Ah-Fong 2009). Studies in $P$. infestans have shown that a plasmid usually integrates in tandem arrays at a single locus (Judelson 1993). Microprojectile bombardment and Agrobacterium-based methods for transformation have also been described (Cvitanich and Judelson 2003; Wu et al. 2016).

To date, the functions of about 40 Phytophthora genes have been tested through overexpression or homology-dependent silencing studies, including genes encoding effectors and diverse cellular proteins (Bos et al. 2010; Hardham and Blackman 2018). The latter method entails knocking down messenger (m)RNA levels of a target gene by expressing sense, antisense, or hairpin sequences from that gene in a stable transformant (Ah-Fong et al. 2008). The expression of hairpin sequences has also been referred to as DNA-directed RNAi by some researchers (Rice et al. 2005). Despite such advances, transformation remains challenging. Many researchers describe difficulty in obtaining sufficient numbers of transformants, transgene expression can be unstable, and the frequency of effective knockdowns can be low. It is, thus, common for 
studies of gene function to be based on a small number of transformants, sometimes as few as one. This is risky, since phenotypes may be caused by unexpected events. About $20 \%$ of $P$. infestans transformants exhibit reduced fitness (Judelson et al. 1993b), which, based on studies of other organisms, might result from mutations caused by plasmid integration (Meng et al. 2007). Oomycetes are normally diploid with complex genomes in which gene-dense clusters are surrounded by repetitive DNA (Haas et al. 2009). For example, the $240-\mathrm{Mb}$ genome of $P$. infestans contains about 18,000 genes and $74 \%$ high-copy sequences (Haas et al. 2009). Although the integration of plasmids into oomycete chromosomes is believed to involve nonhomologous recombination, no studies have described where plasmids integrate. It is unknown whether plasmid DNA inserts preferentially into genedense, gene-sparse, intragenic, or intergenic regions.

Although the mechanism of homology-based silencing has been studied in only a few cases, in P. infestans, this has been shown to result in small RNA production followed by transcriptional silencing and the formation of repressive chromatin (heterochromatin) at the target site (Ah-Fong et al. 2008; Judelson and Tani 2007; van West et al. 2008). Studies in plants and animals indicate that repressive chromatin can move along a chromosome, although its effect on endogenous genes is limited by barrier insulators or regulated by transcription factors (Elgin and Reuter 2013; Le Thomas et al. 2013). In contrast, transgenes or translocated native genes usually lack such protections and, thus, can become silenced by the cis spreading of heterochromatin (Talbert and Henikoff 2006). It is reasonable to consider that heterochromatin may spread beyond the target of gene silencing in Phytophthora spp., causing a phenotype to be ascribed to the incorrect gene. We previously used the spreading phenomenon to our advantage by knocking down a cluster of genes in the same metabolic pathway (Abrahamian et al. 2016). However, no study has examined how often silencing spreads in cis from a target to an unintended gene in any oomycete. Similarly, whether silencing affects off-targets elsewhere in the genome has remained unexplored.

The goal of this publication is to provide data to promote the wise use of transformation in oomycetes, although our findings are also relevant to other systems. We first describe the mapping of transgene integration sites in $P$. infestans using targeted DNA sequencing. Insertions occurred in both gene-rich and gene-poor regions, with a disproportionate fraction residing near the $5^{\prime}$ ends of genes. We also present data from homologydependent silencing studies of 12 genes to show how often silencing spreads from the intended locus. Genes spaced within $500 \mathrm{nt}$ of the target were frequently cosilenced, but there were exceptions, and cosilencing usually did not occur in all transformants. Off-target effects against unlinked genes appeared to be infrequent. Thus, gene silencing and transformation can be reliable technologies but must be used with prudence.

\section{RESULTS}

\section{Identifying locations of transgene insertions.}

Transformants of $P$. infestans were selected from two prior studies, one focused on silencing the INFI elicitin gene and another on expressing the $\beta$-glucuronidase (GUS) reporter (AhFong et al. 2008; Judelson 1993). Transformants from the first study, denoted in this paper with the prefix $S$, were generated using a plasmid that expresses $I N F 1$ sequences driven by the promoter from the Ham34 gene of Bremia lactucae (Judelson et al. 1992) to trigger silencing. This plasmid also expresses nptII driven by the $H s p 70$ promoter of B. lactucae to confer G418 resistance. The second group of transformants, named with a $\mathrm{G}$ prefix, were obtained by a cotransformation experiment using EcoRI-linearized pTH209, which expresses nptII behind the Hsp70 promoter, and EcoRI-linearized pHAMT35G, which expresses uidA (GUS) driven by the Ham34 promoter. Prior studies showed that linearized plasmids usually ligate to each other, circularize, and integrate at a single locus (Judelson 1993).

To identify the plasmid insertion sites, genomic DNA was analyzed with the aid of targeted sequencing. Illumina libraries were enriched for plasmid-containing inserts by affinity purification, using biotinylated 120-nt oligonucleotides, and were sequenced to obtain 100-nt paired-end reads. The insertion sites were then mapped by a two-stage process. First, we detected paired-end reads where one read matched $P$. infestans genomic DNA and the other matched plasmid DNA. The approximate insertion site was then defined by the $3^{\prime}$ end of the assembled $P$. infestans sequences. Since the average insert size of the libraries was about $240 \mathrm{nt}$, the boundary between genomic and plasmid DNA calculated in this manner should be fairly close to the true insertion site. In the second stage of analysis, the precise junction was defined by searching for single reads that were chimeras of $P$. infestans and plasmid sequences, for example, where $40 \mathrm{nt}$ of a 100-nt read was of plasmid origin and the remaining $60 \mathrm{nt}$ matched $P$. infestans DNA. There appeared to be insertions at a single site per transformant, including in the transformants obtained by cotransformation of two plasmids, which is consistent with our prior studies of $P$. infestans transformation (Judelson 1993).

The targeted sequencing approach allowed insertion sites to be identified in seven $\mathrm{S}$ and three $\mathrm{G}$ transformants (Fig. 1, inverted triangles). Eight of the sites were validated by PCR using primers based on the left and right arms of each junction region (Fig. 2). In transformants G2 and G3, it was difficult to identify the precise insertion site, since the apparent junction sequences contained highly conserved repetitive DNA; attempts to confirm the sites by PCR failed since the reactions yielded smears of bands, as shown for G3 in Figure 2. BlastN and BlastX analysis of the repetitive sequences at the G2 junction against GenBank identified matches to reverse transcriptases, suggesting that the integration had occurred in a retroelement-like region. The sequence at the G3 junction lacked significant matches.

An eleventh insertion site (G4) was identified using wholegenome Illumina sequencing (Fig. 1). This involved analyzing approximately 10 -fold sequence coverage of 12 progeny from a cross in which one of the parents was a GUS-expressing transformant (Matson et al. 2015). Plasmid sequences were detected in five of the 12 progeny; the 5:7 segregation ratio is not significantly different $(P=0.56)$ from what would be expected for a single-site insertion. The junction sequence was identified by searching for reads containing both plasmid and genomic DNA. The same junction was identified in multiple progeny, supporting its authenticity.

\section{Genomic and biological context of insertions.}

Three of the integration events were in gene-dense regions and eight in gene-sparse regions, although two of the latter (S1, $\mathrm{S} 4$ ) were within $1 \mathrm{~kb}$ of the $3^{\prime}$ ends of genes (Fig. 1). There was no obvious correlation between plasmid copy number and the density of genes near the insertion site. Each of the 11 events was on a unique supercontig in the $P$. infestans assembly. None of the $\mathrm{S}$ transformants had integrated at the native INF1 locus, which matched sequences on the plasmid. Since the G2 and G3 insertions were difficult to confirm due to repetitive DNA, the locations shown in Figure 1 represent one of 15 to 20 possible insertion sites. Nevertheless, each candidate region in G2 and G3 was repeat-rich and gene-poor. 
Three of the 11 integration events were predicted to affect the expression of a native $P$. infestans gene. In S5 and G1 these were within the open reading frames of genes PITG_05678 and PITG_06920, which encode a conserved protein of unknown function and a Golgi transport protein, respectively. These insertions would, thus, result in aberrant or dysfunctional proteins. In S7, the plasmid integrated near the 5' end of PITG_14392, which encodes a ubiquitin protease. The insertion was $295 \mathrm{nt}$ upstream of the start codon and $270 \mathrm{nt}$ upstream of the transcription start site, based on mapping RNA-seq reads. The adjacency of the insertion to the regulatory region of PITG_14392 may influence expression of that gene.

The phenotypes of the transformants (Fig. 1, right column) were checked for an association with the nature of the integration event. There was a hint of a relationship between the site of insertion in the $\mathrm{S}$ strains and whether the native INFI gene had been silenced. Neither transformant in which the integration was in or near a gene (S5, S7) was silenced for INF1. This may be because homology-dependent silencing in $P$. infestans usually affects the expression of both the native gene and transgene (Ah-Fong et al. 2008; van West et al. 1999), which may have been lethal if repressive chromatin had spread to any of the flanking genes. Although the number of insertion sites successfully mapped in $\mathrm{G}$ transformants was low (several failures in targeted sequencing are not described here), there was not an obvious correlation between phenotype and the site of integration. G1 and G4, which expressed the GUS-encoding transgene for more than two years, had integrations in gene-dense and gene-sparse regions, respectively. G2 and G3, which expressed GUS for about a month before losing activity, contained the insertion in a gene-sparse region. We previously showed that transformants that stop expressing GUS still maintain the gene (Judelson and Whittaker 1995), and this was confirmed by our sequencing data.

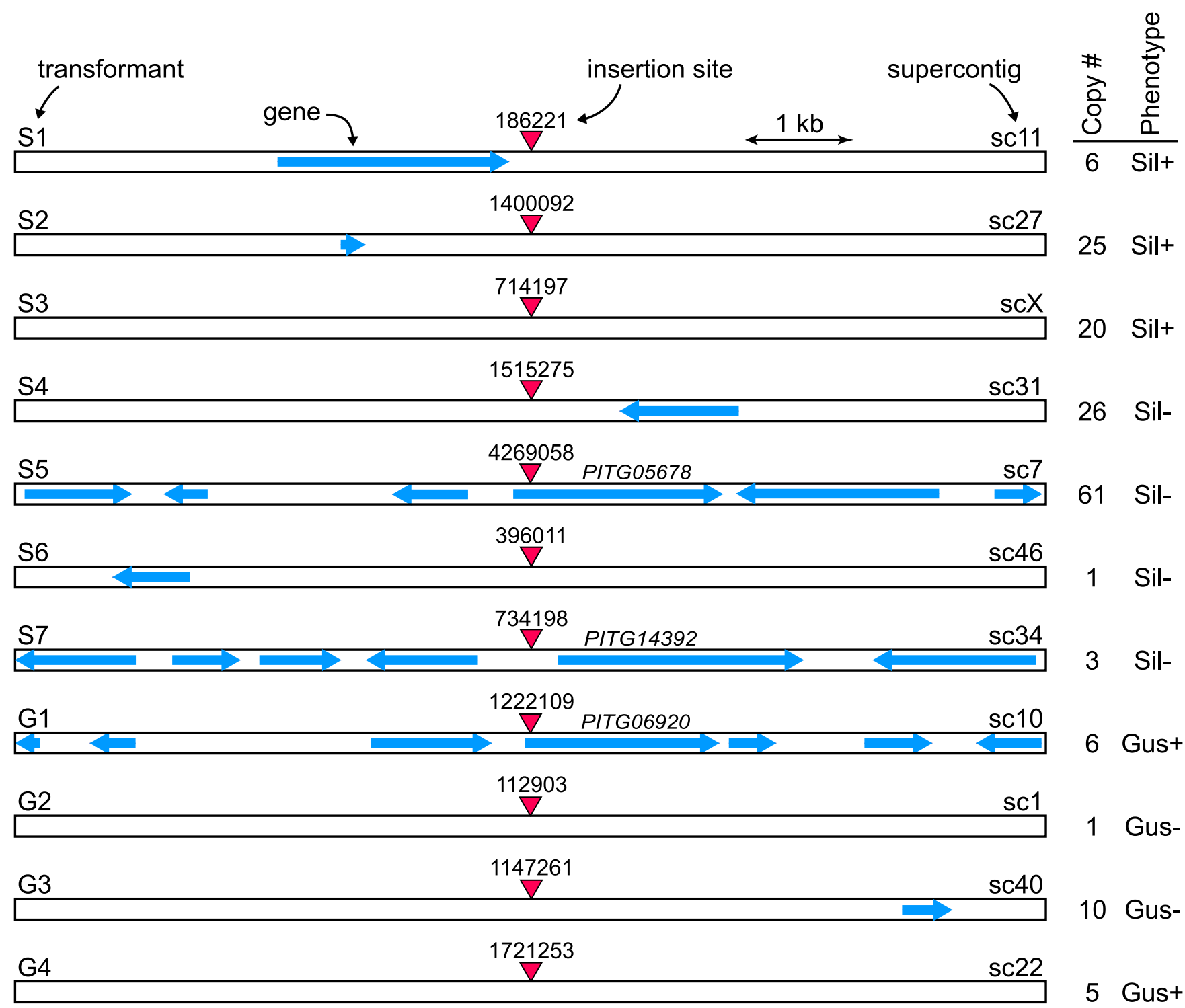

Fig. 1. Plasmid integration sites in Phytophthora infestans transformants. Insertion sites of the $\mathrm{S}$ and $\mathrm{G}$ transformants are marked by inverted triangles, with numbers above each triangle denoting the position on supercontigs from the assembly of strain T30-4 (sc). Arrows represent the coding sequences of genes, with three genes predicted to affect the expression of a native P. infestans gene labeled with the PITG prefix. The columns on the right indicate plasmid copy numbers and phenotypes. Phenotypes are INF-silenced (Sil+) and nonsilenced (Sil-) for S strains and, for G strains, these are GUS-expressing (Gus+) or strains in which GUS activity was short-lived (Gus-). The insertion in S3 was in a region absent from the T30-4 assembly but was in an assembly of strain 1306. 


\section{Detection of microhomology at many insertion sites.}

The sequences of the confirmed junctions are shown in Figure 3. In five cases, some conservation was observed between genomic and plasmid sequences at the site of recombination. This included an 8-nt region of identity (5'-GGAGCGTT) in transformant S1, a 3-nt region in S3 (AGC), and 2-nt regions in S7 (AA), G1 (CT), and G4 (GC). Microhomology was not seen at the sites of the other events. In $\mathrm{S} 2$, one base at the junction did not match sequences in plasmid or genomic DNA and might be the product of DNA repair or a polymorphism arising during culture. The base composition of the 8-nt regions flanking the junctions was slightly skewed, averaging $27 \%$ A, $21 \%$ C, $34 \% \mathrm{G}$, and $18 \%$ T. Skewed base composition near transgene insertion sites has been reported previously in other species (Brunaud 2002).

Frequency of the longitudinal extension of gene silencing.

We examined 38 strains of $P$. infestans from silencing studies of 12 target genes to assess how often transcriptional silencing spread to neighboring loci. This used both newly generated silenced strains and those saved from prior projects (Table 1). Genes that flanked the silencing target were identified and their expression was measured by reverse transcription-quantitative PCR (RT-qPCR) or genome-wide studies, i.e., RNA-seq. The flanking genes were identified using annotations in the $P$. infestans reference assembly (strain T30-4) and comparisons with an assembly of isolate 1306 , which was the progenitor of
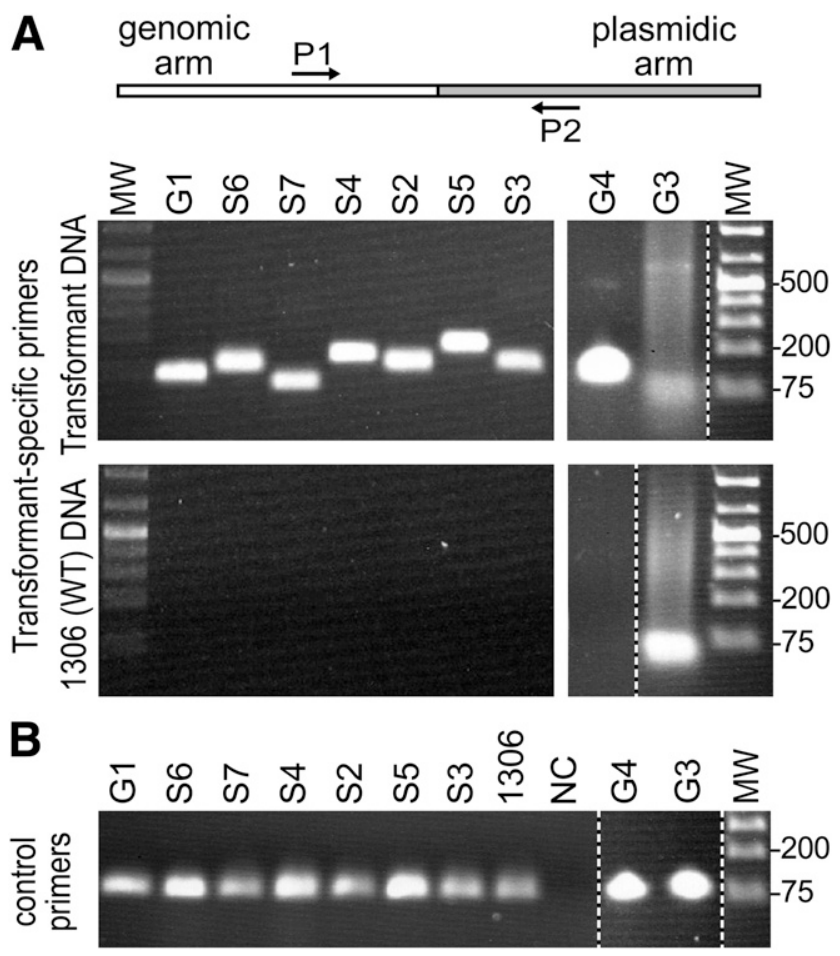

Fig. 2. PCR validation of insertion sites. A, Amplification using primers flanking the plasmid-chromosome junction. As shown in the diagram, primers $\mathrm{P} 1$ and $\mathrm{P} 2$ are within genomic and plasmidic DNA to the left and right of the bioinformatically predicted recombination site, respectively. The top row of images shows reactions using transformant DNA with transformant-specific primers. The bottom row of images are negative controls using each primer set against DNA from progenitor strain 1306. Lane MW is a DNA ladder. The panels on the right came from a separate gel; dashed lines indicate where some lanes were reordered or blank lanes were excised. B, Amplification of genomic DNA using primers against PITG_09862, which serves as a positive control for DNA quality. NC is a no-template control. the transformants. The results are presented in Figure 4 , in which each graph represents a unique transformant.

The analysis of cases in which the genes subjected to silencing were fairly far $(>7 \mathrm{~kb})$ from their neighbors led to the conclusion that silencing is unlikely to spread over many kilobases. For example, the gene silenced with a hairpin in Figure 4A (PITG_11668) resided $10 \mathrm{~kb}$ from its left- and right-most neighbors (PITG_11666 and PITG_11671), which maintained normal levels of expression. A similar outcome is shown in Figure 4B, in which a hairpin against PITG_11664 did not lead to the repression of its flanking genes. Analysis of the transformant in Figure 4C, in which PITG_09198 was targeted, led to the same conclusion. In this case, the hairpin had 98 to $99 \%$ nucleotide identity to seven genes distributed within a 54-kb cluster. Each of the seven genes became cosilenced, probably due to the direct effect of the hairpin. In contrast, genes on the left and right flanks of the cluster (PITG_15172 and PITG_09196) and an intervening gene (PITG_14821) maintained normal levels of expression. These transformants were reported in a prior study (Gamboa-Meléndez et al. 2013).

A situation where the flanking genes were close to the targeted locus is presented in Figure 4D. In this case, PITG_07059 was silenced in five transformants using a sense construct (Fig. 4D1 to D5) and in one using a hairpin (Fig. 4D6). In the first three transformants, normal mRNA levels were displayed by both neighboring genes, which were 139 and 852 nt from genomic arm breakpoint plasmidic arm S1 GGCTTATGAGGTGAGT GGAGCGTTGAGCGACACGATCTTG PLAS CGTCAGCTCGCAGTCG GGAGCGTTGAGCGACACGATCTTG 1306 GGCTTATGAGGTGAGT GGAGCGTTTCTGCGACGGGGTCAC

S2 TTGTACGCACCACATGTGCACACATACACTGCTGCCAGTG PLAS CAAGAACTCTGTAGCACCGCTACATACACTGCTGCCAGTG 1306 TTGTACGCACCACATGTGCTTCGATAAGACGTACTTTTCG

S3 GCCAAGCATTCCTCGTTTAGCGGAAGAGGCCCAATACGC PLAS CGAGTCAGTGAGCGAGGA AGCGGAAGAGCGCCCAATACGC 1306 GCCAAGCATTCCTCGTTT AGC AAATTCATCGCCTTCGAAT

S4 ACTTGGACGGATTTGCTGTGACCGCTACCAGCGGTGGTTT PLAS TGCTTGCAAACAAAAAAACCACCGCTACCAGCGGTGGTTT 1306 ACTTGGACGGATTTGCTGTGGTGGCCATAGTGTTGGTCAG

S5 GGATTTCGTTTTTGTCGATGACCGGATAAGGCGCAGCGGT PLAS TTGGACTCAAGACGATAGTTACCGGATAAGGCGCAGCGGT 1306 GGATTTCGTTTTTGTCGATGGAGATTCAAATTCAAGTCCA

S6 ACAGTCGACGAGGCATGAAGAACTATTAAAGAACGTGGAC PLAS TTCCAGTTTGGAACAAGAGTCACTATTAAAGAACGTGGAC 1306 ACAGTCGACGAGGCATGAAGAAGAAAAACAGGCTCAAAGG

S7 CGTAACGCAATAAAGGCAGAATAGCGACGCACACGTAGAC PLAS CGGCTGAGCGCGCTGAGTC AA TAGCGACGCACACGTAGAC 1306 CGTAACGCAATAAAGGCAG AAAAGGGAGCCTAATTTCCAG

G1 CGCATGCTTGACTTTAACTCTTTGAGTGAGCTGATACCGC PLAS CTGTGGATAACCGTATTACCTTTGAGTGAGCTGATACCGC 1306 CGCATGCTTGACTTTAACTCTGAAAGCGCTGAAAGCGCTG

G4 GGTTGAATCATGAGTTGGTGCGGACAGGTATCCGGTAAGC PLAS GCTTCCCGAAGGGAGAAAGGCGGACAGGATCCGGTAAGC 1306 GGTTGAATCACGAGTTGGTGCATGTCAAGCGGGATTGGAA

Fig. 3. Sequences flanking integration sites. The top, middle, and bottom lines of each alignment correspond to the genomic from each transformant (e.g., S1), the plasmid (PLAS), and the progenitor strain (1306). Shaded bases to the left or right of the boxed bases indicate sequences in the transformant that originate from genomic and plasmid DNA, respectively. The breakpoints between genomic and plasmid DNA are marked by boxes and inverted triangles. The boxes indicate regions of microhomology between plasmid and genomic DNA. 
PITG_07059. However, one or both neighbors were repressed by about $50 \%$ in the transformants shown in Figure 4D4, D5, and D6. This was seen in two biological replicates. The divergent outcomes between strains indicate that there is some randomness or transformant-specific variation in how silencing is imposed.

A second example in which the flanking genes are close to the targeted locus is shown in Figure 4E. These strains were obtained using a hairpin construct based on PITG_01718. In both transformants, the knockdown effect did not spread to the right-flanking gene, which was $400 \mathrm{nt}$ from the target of the hairpin. The left-flanking gene was expressed at normal levels in one transformant (Fig. 4E1) but was repressed by about $50 \%$ in the other (Fig. 4E2). The partial knockdown of the leftflanking gene was observed in two biological replicates.

Similar results were observed in transformants silenced with a hairpin from PITG_16100 (Fig. 4F). In this case, each flanking gene was about $400 \mathrm{nt}$ from the targeted gene. In the four transformants in Figure 4F1 to $\mathrm{F} 4$, both flanking genes were expressed at normal levels. However, the left neighbor was repressed by about $40 \%$ in the two transformants in Figure 4F5 and F6. This was observed in two biological replicates.

A complex outcome was seen when transformants silenced for a clustered gene family was studied (Fig. 4G). These strains were previously used to show that silenced loci undergo heterochromatinization (Judelson and Tani 2007). The three genes in the cluster have about $80 \%$ overall nucleotide identity, with $>95 \%$ identity within their middle and $3^{\prime}$ ends. A full-length hairpin made from PITG_11238 was found to also knock down PITG_11237 and PITG_11239 by nearly 100\% (Fig. 4G1 and G2). A full-length hairpin based on PITG_11237 that strongly silenced its target partially knocked down PITG_11238 and PITG_11239 but only by 50 to $75 \%$ (Fig. 4G3). In contrast, the genes flanking this cluster exhibited normal levels of transcription, including PITG_11236, which was 996 nt away and may share a promoter with PITG_11237. These results were confirmed in two biological replicates. Several processes may explain how silencing occurred within this gene family. Cluster-wide silencing may have been caused by the hairpin directly or by broadcasting repressive chromatin from one of the genes. The partial knockdown of PITG_11238 and PITG_11239 in the strain in Figure 4G3 might be due to incomplete repression within each nucleus or heterogeneous nuclear states resulting in variegated expression, similar to that observed in plants and animals (Timms et al. 2016).

A situation in which silencing usually spread to the neighboring genes is shown in Figure $4 \mathrm{H} 1$ and $\mathrm{H} 2$, illustrating cases in which a sense construct designed against PITG_13012 partially knocked down flanking genes PITG_13011 and PITG_13013, which reside about $500 \mathrm{nt}$ from the original target. These transformants were described in a prior report (Abrahamian et al. 2016). The spread of silencing appears to have been limited, as the next-closest flanking genes were not affected. This was observed in three biological replicates. Interestingly, a sense construct based on PITG_13013 caused silencing to spread to PITG_13012 and PITG_13011 (Fig. $4 \mathrm{H} 3$ ). This suggests that repressive chromatin triggered by gene silencing can spread through multiple genes that are unrelated in sequence.

Another example of silencing spreading to adjacent genes is shown in Figure 4I. Each of six strains in which homologydependent silencing was used against PITG_03290 displayed strong downregulation of flanking gene PITG_03291, which is 544 nt away. This occurred with both sense and hairpin constructs. This was observed in at least two biological replicates.

Our final example involves PITG_16104, which was silenced using a hairpin from the $5^{\prime}$ end of the gene (Fig. $4 \mathrm{~J} 1$ to $\mathrm{J} 3$ ) and a hairpin from the $3^{\prime}$ end (Fig. 4J4). These transformants have not been described previously. In each of the four transformants, the left-flanking gene exhibited normal expression even though it was only $666 \mathrm{nt}$ from the targeted gene. Since the neighbor to the right, PITG_16105, was much farther from the target locus ( $3 \mathrm{~kb})$, it was surprising to see that it was down-regulated by about $50 \%$ in each transformant. Interestingly, an analysis of the distribution of RNA-seq reads from isolate 1306 revealed the presence of a noncoding RNA between PITG_16104 and PITG_16105, which is labeled as ncRNA. This was consistently cosilenced with PITG_16104. Therefore, it seems that a repressive chromatin state was cis-propagated through the noncoding RNA locus, which had a mild influence on PITG_16105 transcription.

\section{Off-target effects occurring in trans are infrequent.}

We next focused on the type of off-target effect that, in other organisms, is conventionally associated with gene-silencing

Table 1. Transformants used in this study ${ }^{\mathrm{a}}$

\begin{tabular}{lcccc}
\hline Gene & $\begin{array}{c}\text { Configuration in } \\
\text { silencing construct }\end{array}$ & $\begin{array}{c}\text { Full-length coding } \\
\text { sequence (nt) }\end{array}$ & $\begin{array}{c}\text { Portion in silencing } \\
\text { construct (nt) }\end{array}$ & Source of transformant \\
\hline PITG_01718 & Hairpin & 1,707 & $517-1,016$ & This study \\
PITG_03290 & Hairpin & 1,638 & $1,063-1,556$ & This study \\
PITG_03290 & Sense & 1,638 & $1,063-1,556$ & This study study \\
PITG_07059 & Hairpin & 1,299 & $718-1,196$ & This study; Leesutthiphonchai \\
PITG_07059 & Sense & 1,299 & $718-1,196$ & and Judelson 2018 \\
& & & $255-833$ & Gamboa-Meléndez et al. 2013 \\
PITG_09198 & Hairpin & 1,053 & $1-978$ & Judelson and Tani 2007 \\
PITG_11237 & Hairpin & 978 & $1-1,023$ & Gambon-Meléndez et al. 2013 \\
PITG_11238 & Hairpin & 1,023 & $1-546$ & Gamboa-Meléndez et al. 2013 \\
PITG_11664 & Hairpin & 1,044 & $200-700$ & Ah-Fong et al. 2008 \\
PITG_11668 & Hairpin & 1,101 & $1-376$ & Abrahamian et al. 2016 \\
PITG_12551 & Hairpin & 376 & $1-2,709$ & This study \\
PITG_13012 & Sense & 2,709 & $1-3,141$ & This study \\
PITG_13013 & Sense & 3,141 & $1,129-1,608$ & This study \\
PITG_16100 & Hairpin & 2,085 & $13-512$ & This study \\
PITG_16104 & Hairpin & 1,971 & $897-1,386$ & Judelson 1993; Matson et al. 2015 \\
PITG_16104 & Hairpin & 1,971 & N.A. & Tad
\end{tabular}

${ }^{a}$ Genes PITG_12551 (INF1) and uidA ( $\beta$-glucuronidase) were used to obtain the S and G transformants. The G transformants were obtained by cotransformation with a plasmid encoding $n p t I I$. The other genes were used as targets for the silencing experiments. N.A. $=$ not applicable. 
methods, such as RNAi, which involves the knockdown of genes with partial complementarity to the target. This was explored using strains of $P$. infestans silenced for four of the genes described in the prior section. Rules for predicting off-targets in plants and animals vary but include having $>90 \%$ identity within a 19-nt region, 11 nt of contiguous identical nucleotides, or partial identity within about $15 \mathrm{nt}$, provided that a seed region is conserved (Fellmann and Lowe 2014; Jackson

Key: $\square$ targeted gene $\square$ untargeted neighbor $\square$ silencing construct $\quad \rightarrow$ direction of transcription $\stackrel{4 \mathrm{~kb}}{\longleftrightarrow}$
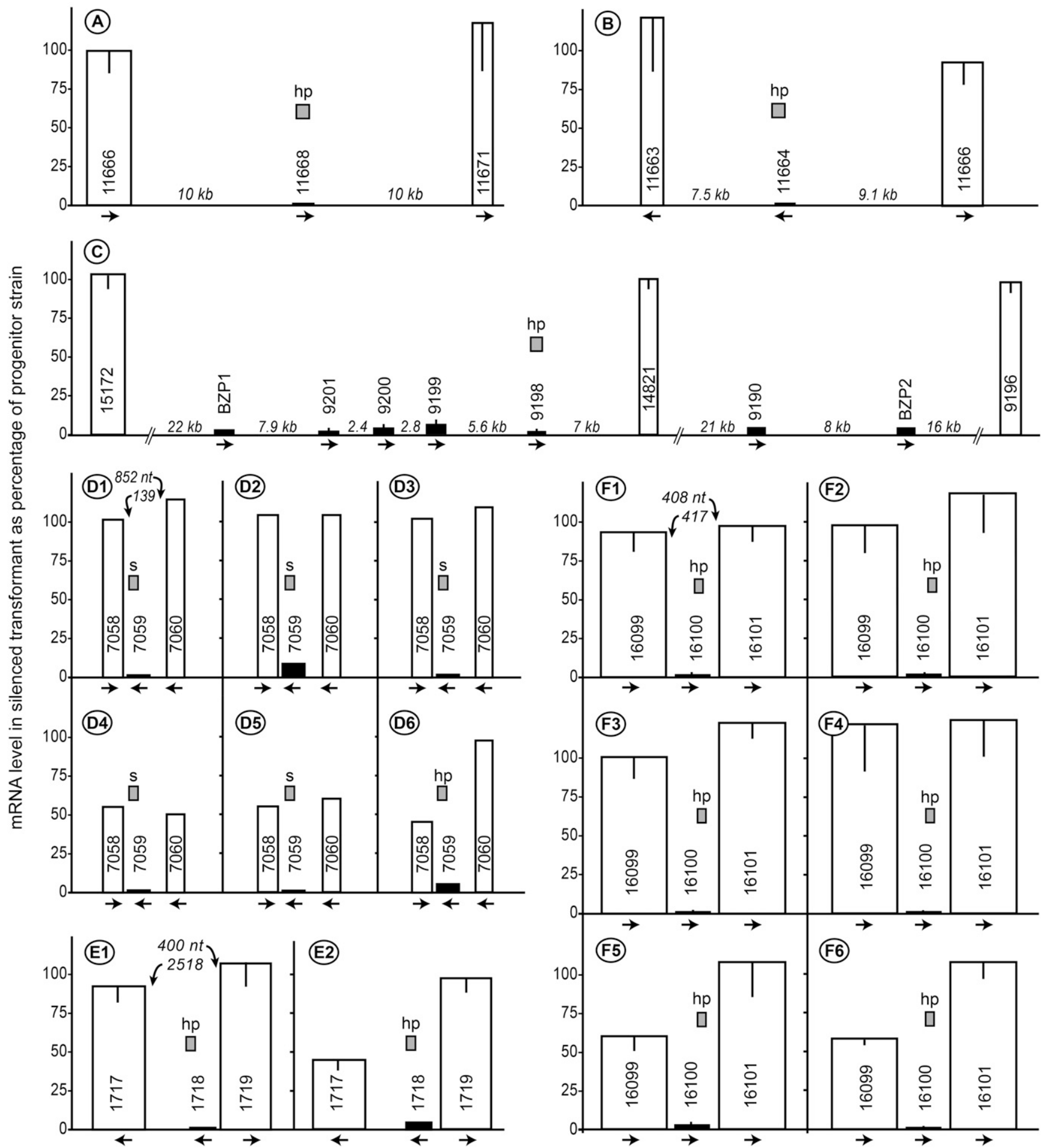
et al. 2006). Consequently, we defined potential off-target genes in $P$. infestans as those having at least $11 \mathrm{nt}$ of identity, 13 to $14 \mathrm{nt}$ of identity with one mismatch, 15 to $19 \mathrm{nt}$ of identity with up to two mismatches, or 20 to 21 nt of identity with up to three mismatches to the silencing construct. Searches for complementarity examined exons, introns, and $60 \mathrm{nt}$ of extra bases at the $5^{\prime}$ and $3^{\prime}$ ends of each gene as potential untranslated regions (UTRs). Whether candidate off-targets were misregulated was assessed by RNA-seq, based on two biological replicates with a minimum of 25 million Illumina reads each. We focused on genes exhibiting a two-fold or greater knockdown compared with controls, since this threshold is commonly used to define short interfering (si)RNA off-targets in mammals (Caffrey et al. 2011; Ui-Tei et al. 2008).

Few, if any, downregulated off-targets were detected in a strain silenced for PITG_11664 with a hairpin (Fig. 5A). Based on sequence analysis, candidate off-targets and nontargets of the hairpin numbered 3,560 and 10,308 genes, respectively. Only one candidate off-target was down-regulated based on thresholds of $P \leq 0.01$ and $50 \%$ repression compared with empty vector controls. The gene, PITG_11131, had 12 nt of identity with the hairpin and an mRNA abundance of $49 \%$ compared with controls. However, this seems to be a false positive. A similar fraction of predicted nontargets (i.e., lacking

Fig. 4. (Continued from previous page)

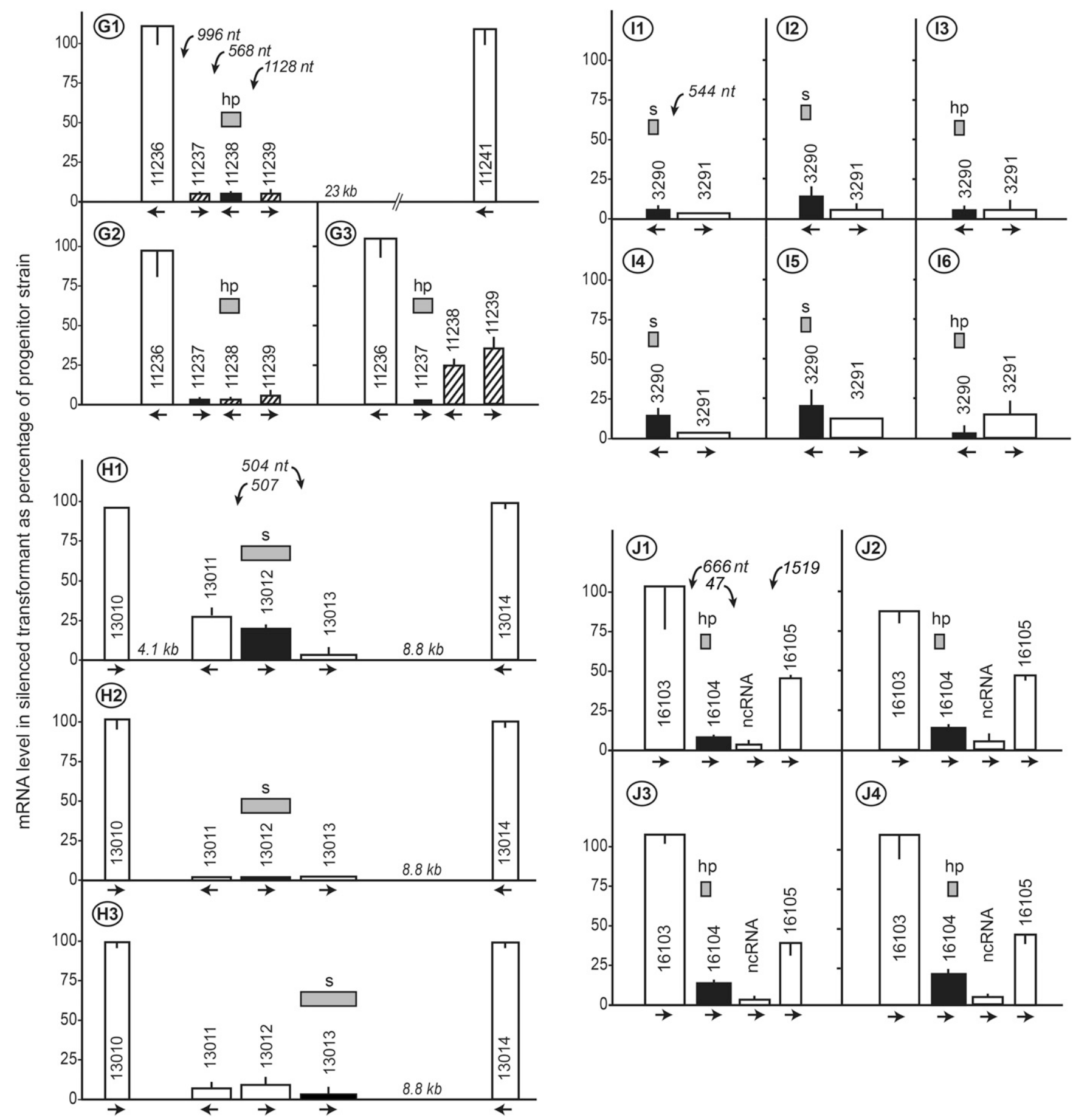


complementarity to the silencing construct) were down-regulated, which is suggestive of normal experimental noise. Also, no offtargets were down-regulated significantly when a BenjaminiHochberg multiple testing correction was applied. Moreover, testing of an additional silenced strain showed that it expressed PITG_11131 at normal levels $(89 \% \pm 24 \%$ of controls $)$.

Little evidence for off-targets was also obtained from studying a transformant silenced using a hairpin against PITG_09198 (Fig. 5B). Of 3,158 candidate off-targets, only two passed the 0.5 -fold reduction threshold with $P \leq 0.01$. One was PITG_12405, which had an 11-nt match with the hairpin and was expressed at $46 \% \pm 3 \%$ of the control level. However,

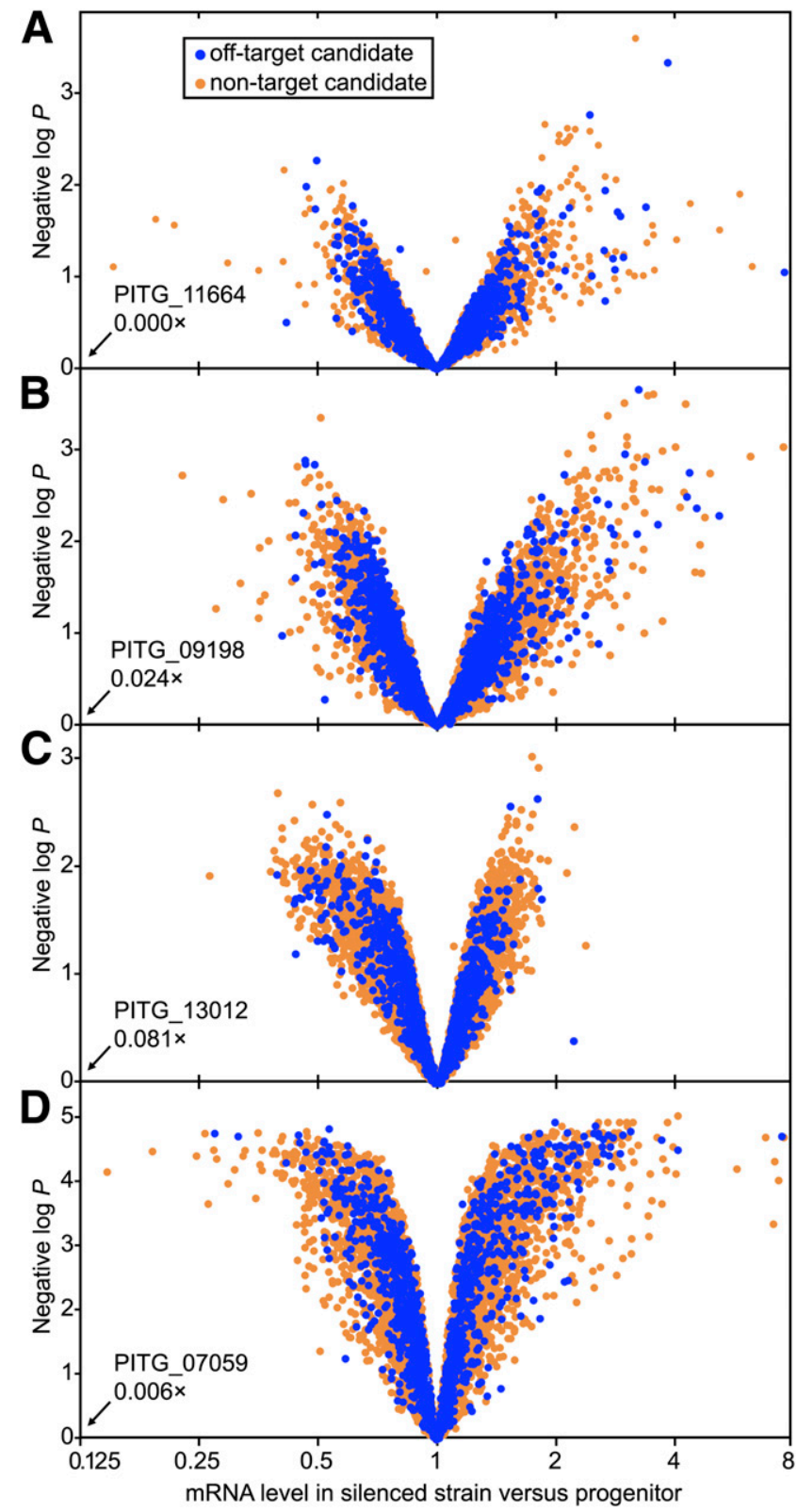

Fig. 5. Effect of silencing on candidate off-target genes. Messenger (m) RNA levels were measured by RNA-seq in transformants silenced with hairpin constructs against A, PITG_11664 or B, PITG_09198 or sense constructs against C,PITG_13012 or D, PITG_07059. Darker dots indicate candidates for off-targets based on partial sequence complementarity; lighter dots indicate other genes (candidate nontargets). The $x$ axis indicates the mRNA level in the silenced strains compared with the nonsilenced control. The extent of silencing of the targeted gene is indicated in the lower left-hand corner of each panel. this is probably a false positive, since it was found to be expressed at $120 \% \pm 11 \%$ of the control level in an additional silenced transformant. PITG_06402 had a 17/19-nt match and was expressed at $47 \% \pm 30 \%$ of the control. In the additional silenced transformant, it was expressed at $71 \% \pm 10 \%$ of control levels. PITG_06402 could be a weak off-target or could be regulated directly by PITG_09198, which encodes a transcription factorlike protein (Gamboa-Meléndez et al. 2013). It should be noted that three genes with 99\% identity to PITG_09198 were silenced by the PITG_09198 hairpin. These are not shown in Figure 5B, since they are considered targets and not off-targets.

Little support for off-targets was also obtained by analysis of a transformant silenced for the nitrate assimilation cluster, which includes genes PITG_13011, PITG_13012, and PITG_13013, which encode a nitrate transporter, nitrate reductase, and nitrite reductase, respectively (Fig. 5C). Only two genes of 1,527 candidate off-targets were potentially down-regulated according to the 0.5 -fold reduction and $P \leq 0.01$ thresholds. One was PITG_08758, which had 12 nt of complementarity with the sense construct and was expressed at $45 \% \pm 3 \%$ of control levels. However, this is probably a false positive, based on the testing of additional biological replicates. The second off-target candidate was PITG_12961, a gene that encodes a transfer RNA synthetase and which had a 15/16 match with the hairpin and was expressed at $48 \% \pm 2 \%$ of the control. The low expression of PITG_12961 persisted in the additional replicates, being $51 \% \pm 4 \%$ of control levels. However, instead of being an off-target effect, this seemed to be a consequence of downregulating the gene cluster. This is because PITG_12961 mRNA was $48 \% \pm 5 \%$ of the control in a strain in which the cluster was silenced using a construct targeting PITG_13013.

Poor support for off-target was also obtained through the analysis of a strain silenced for PITG_07059 using a sense construct (Fig. 5D). PITG_07059 encodes a transcription factor that regulates sporulation, which modulates the transcription of several thousand genes (Leesutthiphonchai and Judelson 2018). The analysis was consequently limited to genes that exhibited less than a twofold reduction during a timecourse of sporulation in wild-type $P$. infestans, using RNA-seq data from samples obtained in a previous study (Xiang and Judelson 2014). This left 1,318 candidate off-targets and 5,177 nontargets for analysis. Nine candidate off-targets appeared to be downregulated by 25 to $50 \%$. However, these were expressed at normal levels in an additional silenced transformant. One interpretation is that the nine genes were false positives due to normal experimental noise, since many predicted nontargets also appeared to be differentially expressed. It is also possible that some of the nine genes are authentic off-targets, but that the effect is random and not seen in all transformants.

We also studied whether genes with 21-mers that have the strongest matches to the silencing construct might be offtargets. This is a simplistic approach, but, in the absence of rules for defining off-targets in oomycetes, this is a strategy that some researchers might currently use. The analysis yielded no evidence for off-target effects. For example, in the transformant silenced for PITG_13012, the 37 genes having 19 or more identical bases per 21 -mer averaged $98 \%$ of the mRNA level of controls, with no individual gene exhibiting $<50 \%$ and only one having $<75 \%$. Similarly, in the transformant silenced for PITG_09198 using a hairpin construct, the 24 genes having a $19 / 21$ or greater match to the hairpin showed an average mRNA level of $97 \%$ versus the controls, with no individual gene having $<50 \%$ expression and only one being $<75 \%$.

Transgenes are not always cosilenced with the target.

Initial studies of homology-dependent silencing in Phytophthora spp. reported that sense, antisense, and hairpin 
constructs became silenced along with their targets, based on RNA blot analysis of a modest number of genes (Ah Fong and Judelson 2003; Gaulin et al. 2002; Judelson and Tani 2007; Latijnhouwers and Govers 2003; van West et al. 1999). Most subsequent research has not distinguished between the transgene and native gene when analyzing transformants from a gene silencing study. However, we recently reported a case in which the target was strongly knocked down while the transgene was strongly expressed (Leesutthiphonchai and Judelson 2018). To explore this in more detail, we examined 12 strains silenced strongly for five genes and used sequences in their $3^{\prime}$ UTRs to differentiate between transcripts of the native gene and transgene. This was possible since each silencing construct used the transcriptional terminator from the Ham34 gene of Bremia lactucae (Judelson et al. 1992).

The results indicated that continued expression of the transgene was not a rare event (Fig. 6). Transcripts from the partial-length sense construct used to silence PITG_07059 were detected in two of three transformants at 119 and $176 \%$, respectively, of the level of expression of the native gene. The phenotypes of the transformants (reduced sporulation) were similar regardless of whether the transgene was persistently expressed (Leesutthiphonchai and Judelson 2018). Expression of the hairpin transcript used against PITG_09198 was detected in one of two PITG_09198-silenced transformants, at 42\% of the level of the native gene. However, transgene mRNA was not detected in three PITG_11664-silenced strains, two PITG_11668silenced strains, and two PITG_13012-silenced strains.

\section{DISCUSSION}

This study focused on the unintended effects of homologydependent silencing experiments in P. infestans and the location of plasmid insertions into chromosomes. We observed that the expansion of silencing to genes residing less than $500 \mathrm{nt}$ from the target was common, while more distant loci usually escaped cosilencing. Protein-coding and noncoding transcription units were both susceptible to the cis-spreading phenomenon. This occurred regardless of whether the neighboring gene was at the $5^{\prime}$ or $3^{\prime}$ end of the target or if the silencing vector encoded sense sequences or a hairpin designed to generate double-stranded (ds)DNA. We therefore recommend that gene-silencing studies include analyses of flanking genes to ensure that inferences about biological function are reliable. Since widening of the silenced zone appeared to be a stochastic event, it should be possible, in most studies, to identify strains that escape cis silencing through more extensive screening. In both genesilencing and overexpression experiments, it is also prudent to ensure that independent transformants yield similar phenotypes in order to exclude artifacts caused by insertions into unexpected genes.

An additional useful product of our research was the observation that transgenes were not always cosilenced with the hairpin or sense construct. Our survey of the literature indicates that many laboratories fail to distinguish between the native locus and transgene when screening transformants from a genesilencing study in Phytophthora spp. This can lead to the mistaken conclusion that strains are not silenced or that the knockdown is only partial. Adjusting RT-PCR screens such that one primer binds to the $3^{\prime}$ UTR is a simple solution. Although the current annotation of the $P$. infestans genome does not include information on UTRs for most genes, this information can be obtained using RNA-seq data that we have deposited in the NCBI database (Bioprojects PRJNA361417 and PRJNA407960).

It is possible that checking for the proximity of the gene of interest to other transcription units may help guide the design of the silencing plasmid. The cis-spread of silencing might be reduced by using shorter sequences or those farther from flanking genes. Smaller constructs might be less effective at triggering silencing, however. We previously showed that a $21-$ nt hairpin silenced $2 \%$ of transformants, compared with $31 \%$ with a 978-nt hairpin from the same gene (Judelson and Tani 2007). The logic of using larger fragments is that not all 21mers are equally potent, so longer sequences would allow Dicer to generate pools of 21-mers, of which some may be more effective than others (Luo et al. 2007).

The multiplicity of siRNAs that are presumably generated by our larger sense and hairpin constructs may also contribute to our finding that few, if any, genes having partial complementarity exhibited off-target effects. In animal knockdowns, pooling siRNAs is believed to reduce sequence-specific offtarget effects by lowering the concentration of each individual siRNA (Hannus et al. 2014). While checking Phytophthora databases for potential off-targets is a prudent practice, it appears that small regions of identity (e.g., a 19/21-nt match) between a gene and 500-nt silencing construct are insufficient to result in a knockdown, although our results do not exclude the possibility of minor effects. Off-target effects are probably also minimized by the fact that the silencing transgene usually becomes transcriptionally quiescent in stable transformants. However, some researchers have reported achieving transient knockdowns in $P$. infestans using dsRNA and whether that causes off-target effects remains to be determined (Whisson et al. 2005).

Results from both sense and hairpin constructs were reported in the present study. We showed previously that hairpin constructs induced silencing three times more often than sense or antisense constructs (Ah-Fong et al. 2008). That conclusion was based on studies of only two genes, but hairpins have also exhibited superior performance in plants (Wesley et al. 2001). Nevertheless, our laboratory has continued to test both types of constructs. The sense plasmid is often an intermediate in making the hairpin and cloning a hairpin in Escherichia coli is sometimes challenging. Therefore, time may be saved by initiating $P$. infestans transformations with a sense construct. A full-length sense plasmid also may yield both silenced and overexpressing transformants.

Analyses of transformants from our published experiments did not reveal cases where unrecognized silencing had spread to flanking genes, which might have negated our conclusions

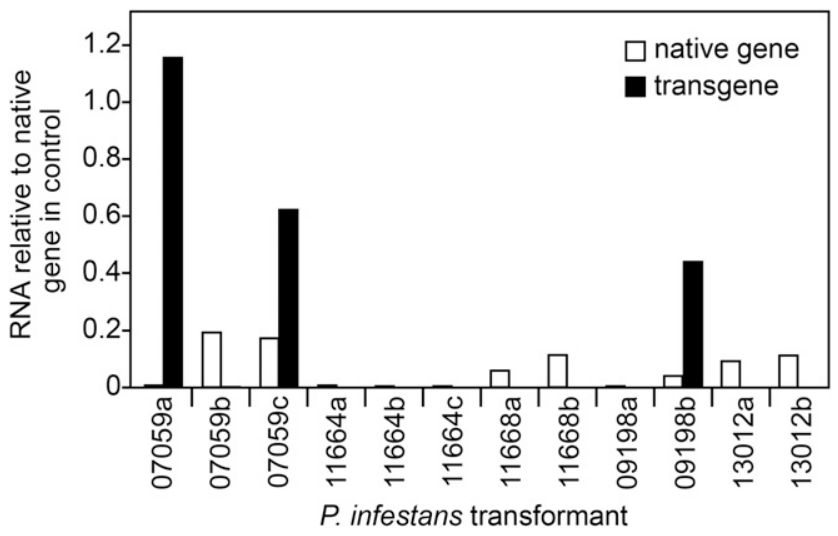

Fig. 6. Expression of the silencing transgene in transformants. Shown are messenger (m)RNA levels in wild-type Phytophthora infestans (WT) and 12 transformants silenced using constructs targeting five $P$. infestans genes; strains silenced using the same plasmid are distinguished by a, b, c following the five-digit identifier of the targeted gene. Messenger RNA levels of the native gene (white bars) and transgene (black bars) are expressed relative to the level of the targeted gene in wild type. Data are based on RNA-seq and reverse transcription-quantitative PCR analysis. 
about the roles of the targeted genes. Luckily, most genes from those historical studies were located $1 \mathrm{~kb}$ or more from their neighbors, beyond the interval in which silencing normally spread. The first native gene that our laboratory silenced, i.e., $\mathrm{PiCdc14}$, was not described in this paper, since it is more than $100 \mathrm{~kb}$ from flanking genes (Ah Fong and Judelson 2003), but our conclusion that $\mathrm{Cdc} 14$ regulates sporulation was confirmed in several species by other researchers (Whisson et al. 2005; Zhao et al. 2011). Unlike PiCdc14, many genes studied by other groups using gene silencing have close neighbors, and the cellular roles of some of those targets may need to be reexamined. About two-thirds of $P$. infestans genes reside in gene-dense zones in which the median intergenic distance is $435 \mathrm{nt}$ (Roy et al. 2013). This is smaller than that of most eukaryotes, such as Arabidopsis thaliana, in which the median intergenic distance is $1.5 \mathrm{~kb}$ (Zhan et al. 2006). Consequently, the expansion of repressive chromatin caused by a genesilencing construct is probably more problematic in Phytophthora spp. than most other eukaryotes.

Our understanding of the machinery that causes silencing and its cis-spread in oomycetes is limited. Homology-based silencing in $P$. infestans has been linked with the transient expression of small RNAs, which arrests transcription based on nuclear run-on assays (Ah-Fong et al. 2008; Judelson and Tani 2007; van West et al. 1999). DNAse protection studies and tests of histone modification inhibitors have suggested that silencing heterochromatinizes the target (Judelson and Tani 2007; van West et al. 2008), although only a few target genes have been studied to date. P. infestans encodes the core components for RNA silencing, namely an RNA-dependent RNA polymerase, two Dicers, and five Argonautes (Asman et al. 2016). Studies in model systems have shown that siRNAs bound to Argonaute guide chromatin-modifying enzymes to complementary loci, leading to transcriptional silencing. Work in fission yeast indicated that siRNA-Argonaute complexes are recruited to their targets through interactions with nascent transcripts (Shimada et al. 2016). The cis-spread of silencing may thus occur along mRNA molecules. In plants, the signal involved in posttranscriptional silencing was shown to extend $3^{\prime} \rightarrow 5^{\prime}$ and $5^{\prime} \rightarrow 3^{\prime}$ for up to 300 and $1,000 \mathrm{nt}$, respectively (Petersen and Albrechtsen 2005; Vaistij et al. 2002). These distances resemble the zone susceptible to the spread of transcriptional silencing in $P$. infestans. Another mechanism for the cis-spread of silencing might involve propagating repressive histone marks. In mammals, histone methyltransferases G9a and GLP forms a complex that binds $\mathrm{H} 3 \mathrm{~K} 9 \mathrm{me}$, which allows the enzymes to read their own marks and spread the modification (Shinkai and Tachibana 2011).

Our data on plasmid integration sites stress the importance of drawing conclusions about gene function from studies of multiple transformants. Three of the 11 mapped insertions $(27 \%)$ were potentially mutagenic, since they were within 300 nt of the start site of $P$. infestans genes, including within coding sequences. Transformants bearing such insertions might be reduced in fitness due to haploid insufficiency. How often this would occur in an oomycete is a matter of conjecture, but about $15 \%$ of human genes are believed to be lethal in a hemizygous state (Lek et al. 2016). There are also precedents of insertions reducing fitness (Durkin et al. 2001). In Phytophthora spp., a single insertion might alter virulence, since effectors are often present in a hemizygous state (Jiang et al. 2006).

The frequency of insertions near the start site of genes in our $P$. infestans transformants occurred more than expected by random chance, as this space represents only $4.3 \%$ of the genome. Studies in Saccharomyces cerevisiae showed that plasmid integration occurred more easily in regions with low nucleosome occupancy, which is common at the $5^{\prime}$ ends of genes (Aslankoohi et al. 2012; Jiang and Pugh 2009). Disproportionate insertions into this area were also described for foreign DNA and transposons in mouse cells and of foreign DNA in Arabidopsis thaliana (Yan et al. 2013; Yant et al. 2005). The latter study also identified microhomology at recombination sites, as we found in P. infestans.

Gene editing systems such as CRISPR/Cas9 provide an alternative to gene silencing. This was recently adapted to $P$. capsici, $P$. palmivora, and $P$. sojae but has not yet succeeded with $P$. infestans (Gumtow et al. 2018; Miao et al. 2018; J. van den Hoogen and F. Govers personal communication). Nevertheless, the silencing method may be advantageous in some situations. For example, an entire gene family may be silenced by a single construct (Grenville-Briggs et al. 2008; Judelson and Tani 2007). Optimizing both tools for functional genomics would benefit studies of oomycetes.

\section{MATERIALS AND METHODS}

\section{$P$. infestans transformation.}

All transformants were obtained using isolate 1306, which is a diploid strain isolated from a tomato field in California. Strains for insertion analysis were obtained using plasmids pHP4 (7.8 kb), pTH209 (4.8 kb), and pHAMT35G (6.0 kb). The latter two were cotransformed into $P$. infestans as linearized DNA, which is normally ligated together and circularized in vivo by $P$. infestans prior to chromosomal integration. Transformants were maintained on media containing 5 to $10 \mu \mathrm{g}$ of G418 per milliliter prior to DNA or RNA extraction. DNA blot analysis, measurements of GUS activity and protein and RNAbased assessments of INF1 silencing in strains used for insertion analysis were described previously (Judelson and Ah-Fong 2009).

Gene-silencing experiments used sense or hairpin constructs expressed from the Ham 34 promoter (Table 1). The isolation of some of these were described previously as noted above. Others were generated using pSTORA (Judelson and Ah-Fong 2009) or a version modified to include additional cloning sites (pSTORAV). Strains were defined as silenced if the mRNA level of the target gene in RT-qPCR was $<25 \%$ that of wild type, based on three biological replicates of wild type and the putative silenced strain.

Transformants were obtained using a modification of our original protoplast method (Judelson et al. 1991). Seed cultures for protoplasting were initiated by spreading about $10^{4}$ sporangia per $150-\mathrm{mm}$ plate of rye-sucrose media containing $1.5 \%$ agar, typically using 15 plates per experiment. After about 10 days at $18^{\circ} \mathrm{C}$ in the dark, $15 \mathrm{ml}$ of room-temperature water were spread on each plate, and sporangia were rubbed from the plate using a flamed bent glass rod. The liquid from the plates was decanted into a 1-liter flask, and hyphal fragments were removed by filtering through $50-\mu \mathrm{m}$ nylon mesh. An equal amount of clarified amended lima bean media (Bruck et al. 1980) was then added, and additional media (and an equal volume of water) were added to set the sporangia concentration to $4 \times 10^{5}$ per milliliter. The media was then distributed to 1 liter flasks, with $150 \mathrm{ml}$ per flask. After 24 to $36 \mathrm{~h}$ of stationary growth at $18^{\circ} \mathrm{C}$, the germinated sporangia had formed a thin mat on the bottom of each flask. These were detached from the glass by gentle swirling and were harvested by pouring the culture through $50-\mu \mathrm{m}$ mesh and rinsing with protoplasting buffer (PB) (0.4 M mannitol, $20 \mathrm{mM} \mathrm{KCl,} 20 \mathrm{mM}$ MES, pH 5.7, $10 \mathrm{mM} \mathrm{CaCl}{ }_{2}$ ). This wash was performed by picking up the hyphae from the mesh with bent forceps, placing the hyphae in a 50-ml tube containing PB, and collecting the hyphae again on the nylon mesh. For every milliliter of packed germlings, $3 \mathrm{ml}$ 
of PB was added, containing $5 \mathrm{mg}$ of filter-sterilized cellulase per milliliter (Sigma) (from Trichoderma reesi) and $10 \mathrm{mg}$ of $\beta$-glucanase per milliliter; the latter was either Vinoflow NCE (Novozyme) or Extralyse (Laffort). The tube was then shaken gently $(40 \mathrm{rpm})$ on an orbital shaker. During this incubation, $30 \mu \mathrm{g}$ of DNA (in $40 \mu \mathrm{l}$, volume adjusted, as needed, with water) was mixed in a polystyrene tube with $60 \mu \mathrm{l}$ of Lipofectin (Thermo). When cell-wall digestion was about $90 \%$ complete, based on microscopic examination, typically about 20 to $25 \mathrm{~min}$, the protoplast mixture was passed through Miracloth or $50-\mu \mathrm{m}$ mesh and was pelleted in a swinging bucket centrifuge at $700 \times g$ at room temperature. The pellet was resuspended gently in $30 \mathrm{ml}$ of $\mathrm{PB}$ and respun. The pellet was then resuspended in $15 \mathrm{ml}$ of $\mathrm{PB}$, and $15 \mathrm{ml}$ of MT (1 M mannitol, $10 \mathrm{mM}$ Tris, $\mathrm{pH}$ 7.5) was added. After another round of centrifugation, the pellet was resuspended in $30 \mathrm{ml}$ of MT plus $10 \mathrm{mM} \mathrm{CaCl}_{2}$, was respun, and was resuspended at about $2.5 \times 10^{7}$ protoplasts per milliliter, based on a concentration determined before the final spin. The DNA was then added to $0.7 \mathrm{ml}$ of the protoplast mixture in a 16-ml polystyrene tube, with gentle mixing by inversion or gentle pipetting up and down. After $4 \mathrm{~min}, 0.7 \mathrm{ml}$ of $50 \%$ polyethylene glycol MW 3350 containing $25 \mathrm{mM}$ $\mathrm{CaCI}_{2}$ and $10 \mathrm{mM}$ Tris, $\mathrm{pH} 7.5$, was added slowly by pipetting the fluid down the side of the tube while rotating the tube. After $4 \mathrm{~min}, 2 \mathrm{ml}$ of clarified rye-sucrose broth containing $1 \mathrm{M}$ mannitol (rye-mannitol) at room temperature was added, the tube was inverted, and, after $1 \mathrm{~min}$, an additional $4 \mathrm{ml}$ of ryemannitol was added. After $1 \mathrm{~min}$, the contents of the tube were poured into $25 \mathrm{ml}$ of additional rye-mannitol (in a plastic petri plate or a $50-\mathrm{ml}$ tube) and the material was incubated for 20 to $36 \mathrm{~h}$ at $18^{\circ} \mathrm{C}$. The regenerated tissue was then spun at $1,000 \times g$ for $5 \mathrm{~min}$. The pellet was then resuspended in about $1.5 \mathrm{ml}$ of media containing mannitol with the aid of agitation, using a 1$\mathrm{ml}$ pipette, and was spread on rye-sucrose agar plates containing $7 \mu \mathrm{g}$ of G418 per milliliter. These plates typically were amended with 40 units of nystatin and $25 \mu \mathrm{g}$ of penicillin $\mathrm{G}$ (or other antibacterial) per milliliter. Colonies typically appeared after 7 days at $18^{\circ} \mathrm{C}$.

\section{Targeted sequencing.}

Library construction and target enrichment followed the protocol described by Faircloth et al. (2012) and Smith et al. (2014), which uses the solution-based probe capture method developed by Gnirke et al. (2009). Genomic DNA was sheared, was size-selected to 200 to $500 \mathrm{nt}$, and was used to prepare sequence-tagged libraries, using the Illumina Truseq kit with barcoded adapters. This was subjected to probe capture using 597 biotinylated 120-mers that had been designed to achieve three-fold coverage against each plasmid; for transformants obtained using two plasmids, a pool of 120-mers from both plasmids were used. Since these must be restricted to one strand of the plasmid to prevent self-annealing during the enrichment procedure, only one side of the plasmid insertion is expected to be mapped unless the plasmid underwent rearrangement in $P$. infestans. After hybridizing the library to the 120-mers, complexes were purified with streptavidin-coated beads and were eluted. After quantifying the enriched libraries, they were pooled and 100-nt paired-end reads were obtained, using an Illumina 2500 instrument, by a commercial provider. The libraries yielded from 296,241 to 6,539,323 clean reads, of which 4 to $45 \%$ matched a plasmid. This was calculated to represent between 80- to 400-fold enrichment, considering the plasmid copy number of each transformant.

After removing adapters and quality trimming, GSNAP was used to map the reads to the $P$. infestans genome and plasmids. This used an assembly of isolate 1306 developed using Pacific Biosciences and Illumina reads (Pan et al. 2018). The matches were then searched to identify read pairs in which one read mapped to the genome and its pair mapped to a plasmid. This was verified using BLASTN. To avoid spurious results, insertions were defined when a minimum of 20 such sequences were identified. The approximate location of the insertion was then identified by assembling the genomic portion of those reads. The coordinates were then converted into the locations in the public assembly of $P$. infestans T30-4, using the BLASTN tool from FungiDB website. Gene locations and, in some cases, transcription start sites were validated by visualizing the distribution of RNA-seq reads using the Integrated Genome Viewer (Thorvaldsdóttir et al. 2013). The reads used have been deposited in NCBI as Bioproject PRJNA361417.

\section{PCR.}

Validation of insertion sites was performed using $20 \mathrm{ng}$ of template DNA, primers designed to amplify junction fragments of 90 to $120 \mathrm{nt}$, and a program of 35 cycles of $94^{\circ} \mathrm{C}$ for $30 \mathrm{~s}$, annealing temperatures of 52 to $58^{\circ} \mathrm{C}$, depending on the primer, for $30 \mathrm{~s}$, and $72^{\circ} \mathrm{C}$ for $30 \mathrm{~s}$. RT-qPCR used primers designed to amplify fragments of 100 to $150 \mathrm{nt}$ from the $3^{\prime}$ ends of the target genes. RNA for RT-qPCR was isolated, using the Sigma kit for plant RNA, was DNase-treated, and cDNA was synthesized using the Maxima (Thermo) first-strand RT-PCR kit. Primers were tested using a dilution series of template and were accepted if efficiencies were above $94 \%$. Amplifications were performed using a Bio-Rad iCycler CFX Connect system using the Dynamo SYBR green qPCR kit (Thermo) with the following program: $95^{\circ} \mathrm{C}$ for $15 \mathrm{~min}$, followed by 40 cycles of $94^{\circ} \mathrm{C}$ for $30 \mathrm{~s}, 52$ to $58^{\circ} \mathrm{C}$ for $30 \mathrm{~s}$, depending on the primer, and $72^{\circ} \mathrm{C}$ for $30 \mathrm{~s}$. Controls without reverse transcription and melt curves were included to help verify the reliability of the amplification. Expression levels were calculated using the $\Delta \Delta$ cycle threshold method, using constitutive genes (PITG_09862 and PITG_11766) (Niu et al. 2018) as a control, with at least two biological replicates with three technical replicates each.

\section{Analyses of flanking genes.}

To study the spread of silencing, we examined the annotation of the P. infestans reference genome, which was generated by Sanger sequencing of strain T30-4 (Haas et al. 2009). Some predicted flanking genes appeared to be unexpressed in isolate 1306 or false annotations, based on a lack of RNA-seq reads from hyphae grown on rich and defined media, media containing fungicides, sporulating hyphae, sporangia, sporangia chilled to induce zoospores, zoospore cysts, mating cultures, and early and late timepoints of potato leaf, tomato leaf, and potato tuber infection (NCBI Bioprojects PRJNA361417, PRJNA407960; unpublished data). When a gene was deemed to be missing or unexpressed in isolate 1306, the next-closest gene was chosen as the flanking locus. If the region flanking the gene of interest in the T30-4 assembly lacked annotated genes or contained gaps, we validated the assembly or filled gaps, using the 1306 assembly (Pan et al. 2018). The filled gaps did not appear to contain genes, except in the case of PITG_09199.

Expression analysis of the targeted genes and their neighbors were usually obtained by RT-qPCR. However, data for PITG_09198,PITG_11664, and PITG_11668 were obtained by RNA-seq with the workflow described previously (Ah-Fong et al. 2017). In brief, a minimum of 25 million reads were obtained per biological replicate, with a minimum of two biological replicates. Reads were aligned and mapped to gene models using Bowtie version 2.2.5 and Tophat version 2.0.14, allowing for one mismatch. Expression and differential expression calls were made with edgeR, using trimmed mean of $\mathrm{M}$ normalization, and a generalized linear model. 


\section{Genome-wide analysis of potential off-targets.}

Candidate off-targets were identified using a modified version of BLASTN against a database of the predicted nascent transcripts of $P$. infestans, with 60 bases added to each end of the predicted gene model to represent UTRs. Searches were performed using expect thresholds of 2,000, a word size of 4, and match and mismatch scores of 3 and 2, respectively. Parameters were modified to exclude gapped alignments and lowcomplexity masking. Expression levels were then studied using RNA-seq or RT-qPCR as described above, except that data were trimmed using a count per million threshold of 2.0 to exclude unreliable signals.

\section{LITERATURE CITED}

Abrahamian, M., Ah-Fong, A. M., Davis, C., Andreeva, K., and Judelson, H. S. 2016. Gene expression and silencing studies in Phytophthora infestans reveal infection-specific nutrient transporters and a role for the nitrate reductase pathway in plant pathogenesis. PLoS Pathog. 12: e1006097.

Ah-Fong, A. M., Bormann-Chung, C. A., and Judelson, H. S. 2008. Optimization of transgene-mediated silencing in Phytophthora infestans and its association with small-interfering RNAs. Fungal Genet. Biol. 45: 1197-1205.

Ah Fong, A. M., and Judelson, H. S. 2003. Cell cycle regulator Cdc14 is expressed during sporulation but not hyphal growth in the fungus-like oomycete Phytophthora infestans. Mol. Microbiol. 50:487-494.

Ah-Fong, A. M., Kim, K. S., and Judelson, H. S. 2017. RNA-seq of life stages of the oomycete Phytophthora infestans reveals dynamic changes in metabolic, signal transduction, and pathogenesis genes and a major role for calcium signaling in development. BMC Genomics 18:198.

Aslankoohi, E., Voordeckers, K., Sun, H., Sanchez-Rodriguez, A., van der Zande, E., Marchal, K., and Verstrepen, K. J. 2012. Nucleosomes affect local transformation efficiency. Nucleic Acids Res. 40: 9506-9512.

Åsman, A. K., Fogelqvist, J., Vetukuri, R. R., and Dixelius, C. 2016. Phytophthora infestans Argonaute 1 binds microRNA and small RNAs from effector genes and transposable elements. New Phytol. 211: 993-1007.

Bos, J. I. B., Armstrong, M. R., Gilroy, E. M., Boevink, P. C., Hein, I., Taylor, R. M., Zhendong, T., Engelhardt, S., Vetukuri, R. R., Harrower, B., Dixelius, C., Bryan, G., Sadanandom, A., Whisson, S. C., Kamoun, S., and Birch, P. R. J. 2010. Phytophthora infestans effector AVR3a is essential for virulence and manipulates plant immunity by stabilizing host E3 ligase CMPG1. Proc. Natl. Acad. Sci. U.S.A. 107:9909-9914.

Bruck, R. I., Fry, W. E., and Apple, A. E. 1980. Effect of metalaxyl an acyl alanine fungicide on developmental stages of Phytophthora infestans. Phytopathology 70:597-601.

Brunaud, V., Balzergue, S., Dubreucq, B., Aubourg, S., Samson, F., Chauvin, S., Bechtold, N., Cruaud, C., DeRose, R., Pelletier, G., Lepiniec, L., Caboche, M., and Lecharny, A. 2002. T-DNA integration into the Arabidopsis genome depends on sequences of pre-insertion sites. EMBO Rep. 3:1152-1157.

Caffrey, D. R., Zhao, J., Song, Z., Schaffer, M. E., Haney, S. A., Subramanian, R. R., Seymour, A. B., and Hughes, J. D. 2011. siRNA offtarget effects can be reduced at concentrations that match their individual potency. PLoS One 6:e21503.

Cvitanich, C., and Judelson, H. S. 2003. Stable transformation of the oomycete, Phytophthora infestans, using microprojectile bombardment. Curr. Genet. 42:228-235.

Doench, J. G., Fusi, N., Sullender, M., Hegde, M., Vaimberg, E. W., Donovan, K. F., Smith, I., Tothova, Z., Wilen, C., Orchard, R., Virgin, H. W., Listgarten, J., and Root, D. E. 2016. Optimized sgRNA design to maximize activity and minimize off-target effects of CRISPR-Cas9. Nat. Biotechnol. 34:184-191.

Durkin, M. E., Keck-Waggoner, C. L., Popescu, N. C., and Thorgeirsson, S. S. 2001. Integration of a $c$-myc transgene results in disruption of the mouse Gtf2ird1 gene, the homologue of the human GTF2IRD1 gene hemizygously deleted in Williams-Beuren syndrome. Genomics 73:20-27.

Elgin, S. C. R., and Reuter, G. 2013. Position-effect variegation, heterochromatin formation, and gene silencing in Drosophila. Cold Spring Harb. Perspect. Biol. 5:a017780.

Faircloth, B. C., McCormack, J. E., Crawford, N. G., Harvey, M. G., Brumfield, R. T., and Glenn, T. C. 2012. Ultraconserved elements anchor thousands of genetic markers spanning multiple evolutionary timescales. Syst. Biol. 61:717-726.

Fellmann, C., and Lowe, S. W. 2014. Stable RNA interference rules for silencing. Nat. Cell Biol. 16:10-18.

Firon, A., Beauvais, A., Latgé, J. P., Couvé, E., Grosjean-Cournoyer, M. C., and D'Enfert, C. 2002. Characterization of essential genes by parasexual genetics in the human fungal pathogen Aspergillus fumigatus: Impact of genomic rearrangements associated with electroporation of DNA. Genetics 161:1077-1087.

Gamboa-Meléndez, H., Huerta, A. I., and Judelson, H. S. 2013. bZIP transcription factors in the oomycete phytophthora infestans with novel DNA-binding domains are involved in defense against oxidative stress. Eukaryot. Cell 12:1403-1412.

Gaulin, E., Jauneau, A., Villalba, F., Rickauer, M., Esquerré-Tugayé, M. T., and Bottin, A. 2002. The CBEL glycoprotein of Phytophthora parasitica var. nicotianae is involved in cell wall deposition and adhesion to cellulosic substrates. J. Cell Sci. 115:4565-4575.

Gnirke, A., Melnikov, A., Maguire, J., Rogov, P., LeProust, E. M., Brockman, W., Fennell, T., Giannoukos, G., Fisher, S., Russ, C., Gabriel, S., Jaffe, D. B., Lander, E. S., and Nusbaum, C. 2009. Solution hybrid selection with ultra-long oligonucleotides for massively parallel targeted sequencing. Nat. Biotechnol. 27:182-189.

Grenville-Briggs, L. J., Anderson, V. L., Fugelstad, J., Avrova, A. O., Bouzenzana, J., Williams, A., Wawra, S., Whisson, S. C., Birch, P. R., Bulone, V., and van West, P. 2008. Cellulose synthesis in Phytophthora infestans is required for normal appressorium formation and successful infection of potato. Plant Cell 20:720-738.

Gumtow, R., Wu, D., Uchida, J., and Tian, M. 2018. A Phytophthora palmivora extracellular cystatin-like protease inhibitor targets papain to contribute to virulence on papaya. Mol. Plant-Microbe Interact. 31:363-373.

Haas, B. J., Kamoun, S., Zody, M. C., Jiang, R. H., Handsaker, R. E., Cano, L. M., Grabherr, M., Kodira, C. D., Raffaele, S., Torto-Alalibo, T., Bozkurt, T. O., Ah-Fong, A. M., Alvarado, L., Anderson, V. L., Armstrong, M. R., Avrova, A., Baxter, L., Beynon, J., Boevink, P. C., Bollmann, S. R., Bos, J. I., Bulone, V., Cai, G., Cakir, C., Carrington, J. C., Chawner, M., Conti, L., Costanzo, S., Ewan, R., Fahlgren, N., Fischbach, M. A., Fugelstad, J., Gilroy, E. M., Gnerre, S., Green, P. J., Grenville-Briggs, L. J., Griffith, J., Grünwald, N. J., Horn, K., Horner, N. R., Hu, C. H., Huitema, E., Jeong, D. H., Jones, A. M., Jones, J. D., Jones, R. W., Karlsson, E. K., Kunjeti, S. G., Lamour, K., Liu, Z., Ma, L., Maclean, D., Chibucos, M. C., McDonald, H., McWalters, J., Meijer, H. J., Morgan, W., Morris, P. F., Munro, C. A., O’Neill, K., OspinaGiraldo, M., Pinzón, A., Pritchard, L., Ramsahoye, B., Ren, Q., Restrepo, S., Roy, S., Sadanandom, A., Savidor, A., Schornack, S., Schwartz, D. C., Schumann, U. D., Schwessinger, B., Seyer, L., Sharpe, T., Silvar, C., Song, J., Studholme, D. J., Sykes, S., Thines, M., van de Vondervoort, P. J., Phuntumart, V., Wawra, S., Weide, R., Win, J., Young, C., Zhou, S., Fry, W., Meyers, B. C., van West, P., Ristaino, J., Govers, F., Birch, P. R., Whisson, S. C., Judelson, H. S., and Nusbaum, C. 2009. Genome sequence and analysis of the Irish potato famine pathogen Phytophthora infestans. Nature 461:393-398.

Hannus, M., Beitzinger, M., Engelmann, J. C., Weickert, M. T., Spang, R., Hannus, S., and Meister, G. 2014. siPools: Highly complex but accurately defined siRNA pools eliminate off-target effects. Nucleic Acids Res. 42:8049-8061.

Hardham, A. R., and Blackman, L. M. 2018. Phytophthora cinnamomi. Mol. Plant Pathol. 19:260-285.

Jackson, A. L., Burchard, J., Schelter, J., Chau, B. N., Cleary, M., Lim, L., and Linsley, P. S. 2006. Widespread siRNA "off-target" transcript silencing mediated by seed region sequence complementarity. RNA 12:1179-1187.

Jiang, C., and Pugh, B. F. 2009. Nucleosome positioning and gene regulation: Advances through genomics. Nat. Rev. Genet. 10: 161-172.

Jiang, D., Zhu, W., Wang, Y., Sun, C., Zhang, K. Q., and Yang, J. 2013. Molecular tools for functional genomics in filamentous fungi: Recent advances and new strategies. Biotechnol. Adv. 31:1562-1574.

Jiang, R. H. H., Weide, R., van de Vondervoort, P. J. I., and Govers, F. 2006. Amplification generates modular diversity at an avirulence locus in the pathogen Phytophthora. Genome Res. 16:827-840.

Judelson, H. S. 1993. Intermolecular ligation mediates efficient cotransformation in Phytophthora infestans. Mol. Gen. Genet. 239:241-250.

Judelson, H. S., and Ah-Fong, A. M. V. 2009. Progress and challenges in oomycete transformation. Pages 435-454. in: Oomycete Genetics and Genomics. K. Lamour and S. Kamoun, eds. John Wiley \& Sons, Inc., Hoboken, NJ, U.S.A.

Judelson, H. S., Coffey, M. D., Arredondo, F. R., and Tyler, B. M. 1993a. Transformation of the oomycete pathogen Phytophthora megasperma 
f. sp. glycinea occurs by DNA integration into single or multiple chromosomes. Curr. Genet. 23:211-218.

Judelson, H. S., Dudler, R., Pieterse, C. M. J., Unkles, S. E., and Michelmore, R. W. 1993b. Expression and antisense inhibition of transgenes in Phytophthora infestans is modulated by choice of promoter and position effects. Gene 133:63-69.

Judelson, H. S., and Tani, S. 2007. Transgene-induced silencing of the zoosporogenesis-specific NIFC gene cluster of Phytophthora infestans involves chromatin alterations. Eukaryot. Cell 6:1200-1209.

Judelson, H. S., Tyler, B. M., and Michelmore, R. W. 1991. Transformation of the oomycete pathogen, Phytophthora infestans. Mol. Plant-Microbe Interact. 4:602-607.

Judelson, H. S., Tyler, B. M., and Michelmore, R. W. 1992. Regulatory sequences for expressing genes in oomycete fungi. Mol. Gen. Genet. 234:138-146.

Judelson, H. S., and Whittaker, S. L. 1995. Inactivation of transgenes in Phytophthora infestans is not associated with their deletion, methylation, or mutation. Curr. Genet. 28:571-579.

Kaelin, W. G., Jr. 2012. Molecular biology. Use and abuse of RNAi to study mammalian gene function. Science 337:421-422.

Latijnhouwers, M., and Govers, F. 2003. A Phytophthora infestans G-protein $\beta$ subunit is involved in sporangium formation. Eukaryot. Cell 2:971-977.

Le Thomas, A., Rogers, A. K., Webster, A., Marinov, G. K., Liao, S. E., Perkins, E. M., Hur, J. K., Aravin, A. A., and Tóth, K. F. 2013. Piwi induces piRNA-guided transcriptional silencing and establishment of a repressive chromatin state. Genes Dev. 27:390-399.

Leesutthiphonchai, W., and Judelson, H. S. 2018. A MADS-box transcription factor regulates a central step in sporulation of the oomycete Phytophthora infestans. Mol. Microbiol. 110:562-575.

Lek, M., Karczewski, K. J., Minikel, E. V., Samocha, K. E., Banks, E., Fennell, T., O’Donnell-Luria, A. H., Ware, J. S., Hill, A. J., Cummings, B. B., Tukiainen, T., Birnbaum, D. P., Kosmicki, J. A., Duncan, L. E., Estrada, K., Zhao, F., Zou, J., Pierce-Hoffman, E., Berghout, J., Cooper, D. N., Deflaux, N., DePristo, M., Do, R., Flannick, J., Fromer, M., Gauthier, L., Goldstein, J., Gupta, N., Howrigan, D., Kiezun, A., Kurki, M. I., Moonshine, A. L., Natarajan, P., Orozco, L., Peloso, G. M., Poplin, R., Rivas, M. A., Ruano-Rubio, V., Rose, S. A., Ruderfer, D. M., Shakir, K., Stenson, P. D., Stevens, C., Thomas, B. P., Tiao, G., Tusie-Luna, M. T., Weisburd, B., Won, H. H., Yu, D., Altshuler, D. M., Ardissino, D., Boehnke, M., Danesh, J., Donnelly, S., Elosua, R., Florez, J. C., Gabriel, S. B., Getz, G., Glatt, S. J., Hultman, C. M., Kathiresan, S., Laakso, M., McCarroll, S., McCarthy, M. I., McGovern, D., McPherson, R., Neale, B. M., Palotie, A., Purcell, S. M., Saleheen, D., Scharf, J. M., Sklar, P., Sullivan, P. F., Tuomilehto, J., Tsuang, M. T., Watkins, H. C., Wilson, J. G., Daly, M. J., and MacArthur, D. G. 2016. Analysis of proteincoding genetic variation in 60,706 humans. Nature 536:285-291.

Luo, Q., Kang, Q., Song, W. X., Luu, H. H., Luo, X., An, N., Luo, J., Deng, Z. L., Jiang, W., Yin, H., Chen, J., Sharff, K. A., Tang, N., Bennett, E., Haydon, R. C., and He, T. C. 2007. Selection and validation of optimal siRNA target sites for RNAi-mediated gene silencing. Gene 395:160-169.

Matson, M. E. H., Small, I. M., Fry, W. E., and Judelson, H. S. 2015 Metalaxyl resistance in Phytophthora infestans: Assessing role of RPA190 gene and diversity within clonal lineages. Phytopathology 105:1594-1600.

Meng, Y., Patel, G., Heist, M., Betts, M. F., Tucker, S. L., Galadima, N., Donofrio, N. M., Brown, D., Mitchell, T. K., Li, L., Xu, J. R., Orbach, M., Thon, M., Dean, R. A., and Farman, M. L. 2007. A systematic analysis of T-DNA insertion events in Magnaporthe oryzae. Fungal Genet. Biol. 44:1050-1064.

Miao, J., Chi, Y., Lin, D., Tyler, B. M., and Liu, X. 2018. Mutations in ORP1 conferring oxathiapiprolin resistance confirmed by genome editing using CRISPR/Cas9 in Phytophthora capsici and P. sojae. Phytopathology 108:1412-1419.

Neelakandan, A. K., and Wang, K. 2012. Recent progress in the understanding of tissue culture-induced genome level changes in plants and potential applications. Plant Cell Rep. 31:597-620.

Niu, X., Ah-Fong, A. M. V., Lopez, L. A., and Judelson, H. S. 2018. Transcriptomic and proteomic analysis reveals wall-associated and glucan-degrading proteins with potential roles in Phytophthora infestans sexual spore development. PLoS One 13:e0198186.

Pan, W., Wanamaker, S. I., Ah-Fong, A. M. V., Judelson, H. S., and Lonardi, S. 2018. Novo\&Stitch: Accurate reconciliation of genome assemblies via optical maps. Bioinformatics 34:i43-i51.
Petersen, B. O., and Albrechtsen, M. 2005. Evidence implying only unprimed RdRP activity during transitive gene silencing in plants. Plant Mol. Biol. 58:575-583.

Rice, R. R., Muirhead, A. N., Harrison, B. T., Kassianos, A. J., Sedlak, P. L., Maugeri, N. J., Goss, P. J., Davey, J. R., James, D. E., and Graham, M. W. 2005. Simple, robust strategies for generating DNA-directed RNA interference constructs. Methods Enzymol. 392:405-419.

Roy, S., Kagda, M., and Judelson, H. S. 2013. Genome-wide prediction and functional validation of promoter motifs regulating gene expression in spore and infection stages of Phytophthora infestans. PLoS Pathog. 9: e1003182.

Shimada, Y., Mohn, F., and Bühler, M. 2016. The RNA-induced transcriptional silencing complex targets chromatin exclusively via interacting with nascent transcripts. Genes Dev. 30:2571-2580.

Shinkai, Y., and Tachibana, M. 2011. H3K9 methyltransferase G9a and the related molecule GLP. Genes Dev. 25:781-788.

Smith, B. T., Harvey, M. G., Faircloth, B. C., Glenn, T. C., and Brumfield, R. T. 2014. Target capture and massively parallel sequencing of ultraconserved elements for comparative studies at shallow evolutionary time scales. Syst. Biol. 63:83-95.

Talbert, P. B., and Henikoff, S. 2006. Spreading of silent chromatin: Inaction at a distance. Nat. Rev. Genet. 7:793-803.

Thorvaldsdóttir, H., Robinson, J. T., and Mesirov, J. P. 2013. Integrative Genomics Viewer (IGV): High-performance genomics data visualization and exploration. Brief. Bioinform. 14:178-192.

Timms, R. T., Tchasovnikarova, I. A., and Lehner, P. J. 2016. Positioneffect variegation revisited: HUSHing up heterochromatin in human cells. BioEssays 38:333-343.

Ui-Tei, K., Naito, Y., Zenno, S., Nishi, K., Yamato, K., Takahashi, F., Juni, A., and Saigo, K. 2008. Functional dissection of siRNA sequence by systematic DNA substitution: Modified siRNA with a DNA seed arm is a powerful tool for mammalian gene silencing with significantly reduced off-target effect. Nucleic Acids Res. 36:2136-2151.

Vaistij, F. E., Jones, L., and Baulcombe, D. C. 2002. Spreading of RNA targeting and DNA methylation in RNA silencing requires transcription of the target gene and a putative RNA-dependent RNA polymerase. Plant Cell 14:857-867.

van West, P., Kamoun, S., van't Klooster, J. W., and Govers, F. 1999. Internuclear gene silencing in Phytophthora infestans. Mol. Cell 3: 339-348.

van West, P., Shepherd, S. J., Walker, C. A., Li, S., Appiah, A. A., GrenvilleBriggs, L. J., Govers, F., and Gow, N. A. 2008. Internuclear gene silencing in Phytophthora infestans is established through chromatin remodelling. Microbiology 154:1482-1490.

Wesley, S. V., Helliwell, C. A., Smith, N. A., Wang, M. B., Rouse, D. T., Liu, Q., Gooding, P. S., Singh, S. P., Abbott, D., Stoutjesdijk, P. A., Robinson, S. P., Gleave, A. P., Green, A. G., and Waterhouse, P. M. 2001. Construct design for efficient, effective and high-throughput gene silencing in plants. Plant J. 27:581-590.

Whisson, S. C., Avrova, A. O., VAN West, P., and Jones, J. T. 2005. A method for double-stranded RNA-mediated transient gene silencing in Phytophthora infestans. Mol. Plant Pathol. 6:153-163.

Wu, D., Navet, N., Liu, Y., Uchida, J., and Tian, M. 2016. Establishment of a simple and efficient Agrobacterium-mediated transformation system for Phytophthora palmivora. BMC Microbiol. 16:204.

Xiang, Q., and Judelson, H. S. 2014. Myb transcription factors and light regulate sporulation in the oomycete Phytophthora infestans. PLoS One 9:e92086.

Yan, B. W., Zhao, Y. F., Cao, W. G., Li, N., and Gou, K. M. 2013. Mechanism of random integration of foreign DNA in transgenic mice. Transgenic Res. 22:983-992.

Yant, S. R., Wu, X., Huang, Y., Garrison, B., Burgess, S. M., and Kay, M. A. 2005. High-resolution genome-wide mapping of transposon integration in mammals. Mol. Cell. Biol. 25:2085-2094.

Zhan, S., Horrocks, J., and Lukens, L. N. 2006. Islands of co-expressed neighbouring genes in Arabidopsis thaliana suggest higher-order chromosome domains. Plant J. 45:347-357.

Zhao, W., Yang, X., Dong, S., Sheng, Y., Wang, Y., and Zheng, X. 2011. Transient silencing mediated by in vitro synthesized double-stranded RNA indicates that $P s C d c 14$ is required for sporangial development in a soybean root rot pathogen. Sci. China Life Sci. 54:1143-1150. 